\title{
Las agrupaciones callejeras del Carnaval de Cádiz, el valor de los espacios no mercantilizados para las relaciones sociales
}

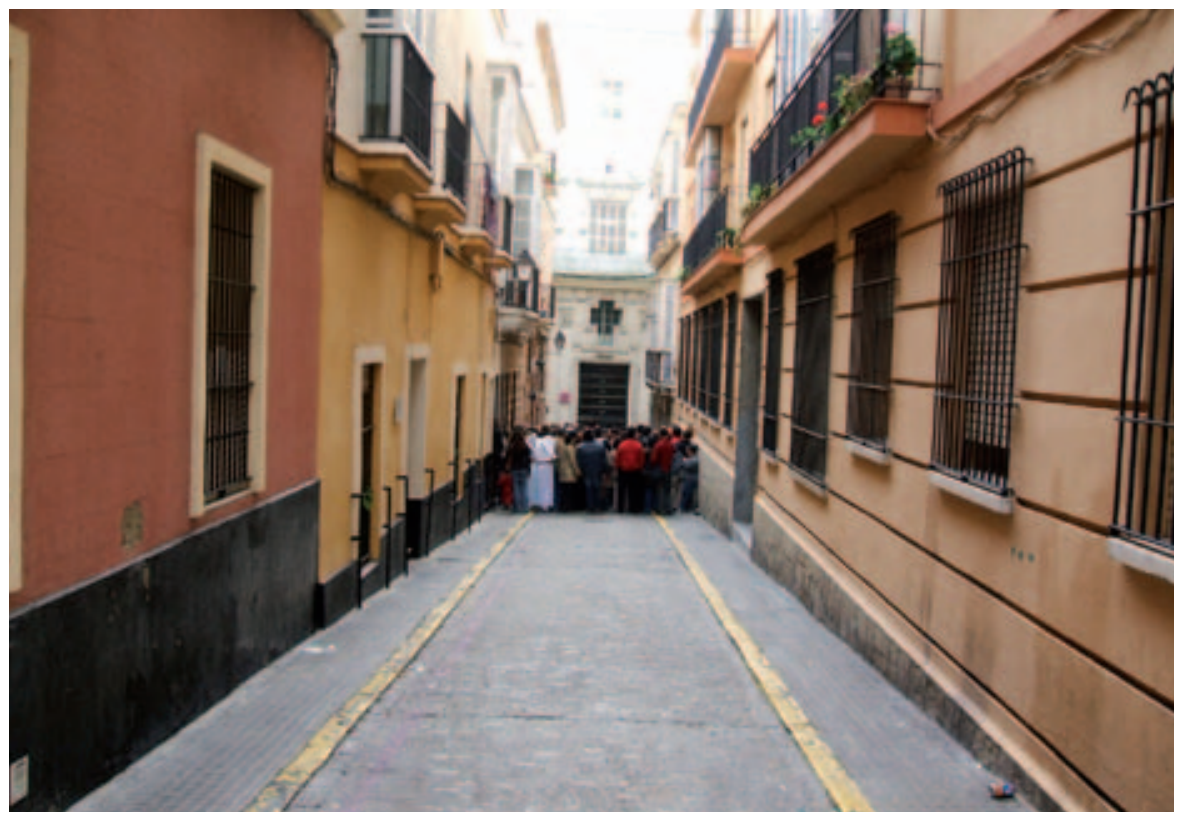

Escuchando. Fotos: Carmen Guerrero Quintero, Abel Al Jende Medina

El Carnaval de Cádiz consolida sus rasgos característicos en el último tercio del siglo XIX y desde entonces cuenta con la copla, interpretada por agrupaciones músico-vocales de distinto tamaño y composición, como elemento central y definitorio. Pero para entender lo que son hoy las agrupaciones callejeras debemos detenernos en el contexto de finales de los años setenta del siglo $X X$, tras cuarenta años de supervivencia de esta fiesta bajo otras formas sin que apareciese nunca mencionada la palabra "carnaval", camuflada e inserta en el repertorio de fiestas típicas y folklóricas del franquismo. Es con los primeros ayuntamientos democráticos cuando se restaura el Carnaval de Cádiz, con una fuerte eclosión de la fiesta $y$, en especial, de las agrupaciones carnavalescas. En las décadas anteriores, participar en una agrupación carnavalesca se relacionaba con las "clases bajas" y la interpretación de sus coplas se había circunscrito al teatro y los espacios cerrados y privados. Sin embargo, en los años de la Transición, la participación en estas agrupaciones se amplia y diversifica en perfiles sociales y sexos, tomando y reivindicando además la calle como espacio fundamental de manifestación, configurándose el caldo de cultivo para la aparición de las Ilamadas agrupaciones "ilegales" o callejeras. A partir de esos años, estas agrupaciones no han dejado de crecer en número y formas.

La irrupción con fuerza del Carnaval de Cádiz y sus agrupaciones se enmarca en un contexto más amplio que la relaciona con fenómenos que se estaban dando simultáneamente en otros lugares de Andalucia y del Estado español en esos años: la recuperación y revitalización de las fiestas y tradiciones populares, de carácter local, con el aumento de forma generalizada de la participación social de la población a través de asociaciones vecinales, otras de diverso fin cultural, movimientos reivindicativos, etc. Este proceso fue potenciado por las nuevas administraciones democráticas, en gran parte ocupadas por los partidos políticos recientemente legalizados y votados, y especialmente por las recién creadas administraciones autonómicas, pues encontraban en las fiestas populares un rico yacimiento de identidad y una manifestación palpable del pueblo al que se disponian administrar.

Desde entonces y en el transcurso de las últimas cuatro décadas, el Carnaval de Cádiz se ha convertido en un importante recurso económico. Por un lado, multitud de pequeñas economias domésticas se nutren formal o informalmente de la fiesta, generándose además un tejido productivo local en torno a la preparación y celebración del carnaval. Por otro, el carnaval sirve a las estrategias de las administraciones que persiguen situar a Cádiz y Andalucia en los diversos mercados globales a los que puede optar. Uno de los principales es el que permite sacar rentabilidad económica de nuestro patrimonio cultural, el mercado turístico.

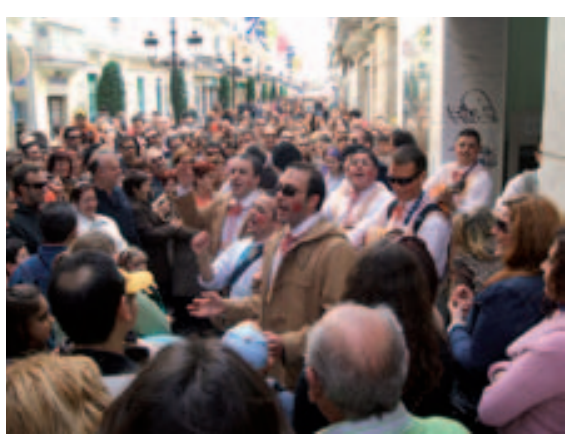

Actuaciones de callejeras entre la muchedumbre del fin de semana
Al modelo de carnaval-espectáculo de alcance internacional y mediático heredado del franquismo y potenciado por las nuevas administraciones', se han sumado instituciones, asociaciones, entidades empresariales o bancarias, y en él las agrupaciones de carnaval han adoptado un papel central. Como resultado, se han multiplicado y siguen aumentando los actos, eventos, certámenes y actividades carnavalescas que conforman una intensa agenda que trata de responder a la masiva afluencia de turistas y visitantes de Cádiz en los días de carnaval y a lo largo de todo el año, esgrimiéndose el carácter carnavalesco gaditano, siempre "sonriente", como uno de los atractivos de la ciudad. Paralelamente, el potencial de la copla de carnaval como recurso expresivo y comunicativo ha sido fomentado por parte de las instituciones que, a través de las televisiones públicas (estatal, en un primer momento, y a lo largo de los años, autonómica y local), han logrado difundir masivamente la copla y las agrupaciones y convertirlas en un gran espectáculo que atrae a un número cada vez mayor de seguidores, dentro y fuera de esta comunidad. Esta difusión masiva ha hecho del Carnaval de Cádiz un modelo de celebración de esta fiesta para toda Andalucia, fraguándose una forma estándar de manifestación cultural, junto a otras fiestas televisadas como la Semana Santa, el Rocío o la Feria de Sevilla.

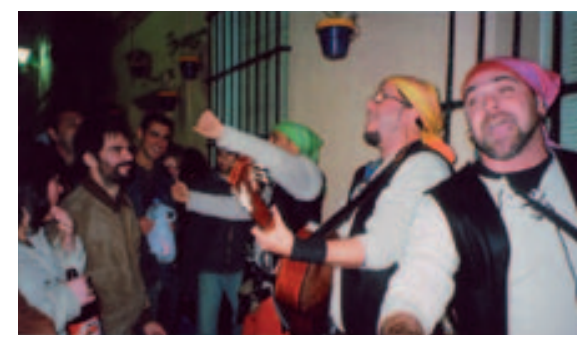

El Capitán Mojarra y sus piratas macarras, chirigota masculina de 2007

En este marco, las agrupaciones callejeras, entendidas como aquellas que no participan en el Concurso Oficial de Agrupaciones Carnavalescas del Carnaval de Cádiz (COAC), siendo una manifestación más informal y espontánea, también ha querido ser integrada en las estrategias de diseño de la marca "Cádiz". De modo que estas agrupaciones se reconocen como otro de los elementos centrales de la fiesta, reivindicado en muchas ocasiones su papel de esencia, de lo más auténtico, y atrayendo asi a otros potenciales visitantes menos interesados en manifestaciones masivas, como la cabalgata o el COAC, y más deseosos de consumir experiencias o vivencias ${ }^{2}$.

La inserción del carnaval y todos los elementos que lo configuran en las estrategias de promoción turistica de la ciudad se basa en procesos que transforman su valor de uso en valor de cambio. Las políticas de 
puesta en valor de las manifestaciones culturales a través de procesos de patrimonialización adoptan el sentido de convertirlas en mercancías para ser vendidas y consumidas, en lugar de servir para el refuerzo de la autoestima colectiva y su reproducción (preservación) a través del uso por y para la gente protagonista de la cultura que vive.

Sin embargo, aunque los discursos institucionales sobre las agrupaciones callejeras estén en sintonía con concepciones mercantilistas que las sitúan como otro recurso más de la fiesta para la venta de la ciudad, lo cierto es que el Ayuntamiento no atiende a las verdaderas necesidades que tienen estas agrupaciones para poder interpretar sus coplas en las calles: poco más que cortar el tráfico por zonas del centro, facilitar a la gente el acceso a urinarios públicos aumentando su número, así como el control de ruidos y música procedentes de los bares del entorno. Estas carencias pueden ser el reflejo de un desinterés por parte del consistorio o del desconocimiento real de cuáles son los códigos básicos de esta manifestación cultural, que requiere determinadas condiciones para expresarse. Condiciones comunicativas que han hecho que otras iniciativas de eventos organizados en torno a las agrupaciones callejeras hayan generado conflictos y contradicciones. Es el caso de la convocatoria Amoscuchá, organizada por un diario de la ciudad y que supone la concentración de agrupaciones callejeras en el barrio del Pópulo algunos dias de la semana de carnaval. La masificación de agrupaciones y público impide, precisamente, que se consiga lo que se persigue: escuchar.

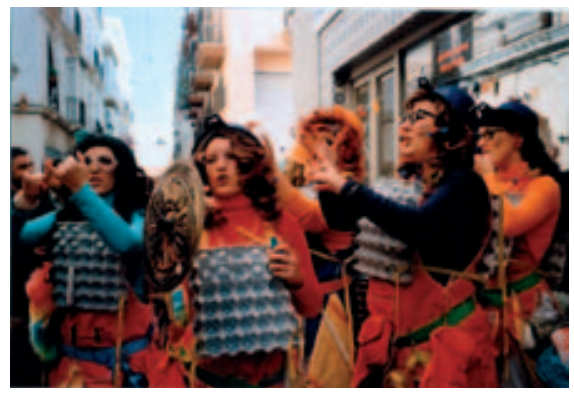

Preparadas para el combate, chirigota femenina de 2008

Pero pese a los intentos de organizarlas o verlas como recurso para las estrategias de marketing de la ciudad, las agrupaciones callejeras constituyen una manifestación de la cultura popular que precisamente está viva porque es inasible para quienes no comparten la trama de significados, desbordándose de itinerarios u horarios preestablecidos; las agrupaciones callejeras son una forma de expresión generadora de espacios para las relaciones sociales cuyos motores (la interacción cara a cara, la risa, la fiesta, los vínculos comunitarios, la memoria compartida...) convierten los sitios en lugares con significado, que no son ni pueden ser aprehendidos por el espacio mercantilizado.

\section{Carmen Guerrero Quintero}

Abel Al Jende Medina

Antropólogos

\section{Notas}

'En 1980 el Carnaval de Cádiz es declarado Fiesta de Interés Turistico Internacional.

${ }^{2}$ Los autores de este texto han realizado un estudio antropológico sobre las agrupaciones callejeras del Carnaval de Cádiz durante los años 2006-2010. Los resultados de esta investigación se han publicado con el titulo En la calle nos vemos (Atrapasueños, 2012; ver sección reseñas de este número)

\section{En la web}

\section{2- 2012. CONSORCIO PARA LA CONMEMORACIÓN DEL II CENTENARIO DE LA CONSTITUCIÓN DE 1812 \\ http://bicentenariocadiz1812.es \\ LÉXICO RELACIONADO CON LA CONSTITUCIÓN 1812 \\ www.rtve.es/alacarta/ videos/saca-la-lengua/saca- lengua-17-03-12/1352104/}

Sitio web de esta organización encargada de gestionar los numerosos actos programados durante el año conmemorativo. El sitio presenta un amplio elenco de recursos sobre la Constitución de 1812. Destacables son los monográficos Un paseo por el Cádiz de La Pepa y Cádiz y los lugares del Doce. De la Puerta de Tierra a Cortadura. Toda una agenda de actos está disponible en esta página: exposiciones, conciertos, rutas, etc. Además dispone de página en Facebook.

LA PEPA 2012. PORTAL EDUCATIVO DE LA JUNTA DE ANDALUCÍA PARA CENTROS DOCENTES NO UNIVERSITARIOS

http://portal.ced.junta-andalucia.es/ educacion/webportal/web/la-pepa/ presentacion

Sitio web creado por la Consejería de Educación de la Junta de Andalucía para acercar a los jóvenes al mejor conocimiento de la Constitución 1812. Recorrido histórico, unidades didácticas para primaria y secundaria, colección de cómics sobre el tema, maquetas y actividades para centros, son algunos de los recursos que ofrece el sitio.
Programa Saca la lengua de TVE emitido el 17 de marzo de 2012. Aborda el léxico relacionado con la Constitución de 1812, contiene entrevistas al periodista Juan José Téllez, al gastrónomo Manuel Ruiz y al popular letrista Antonio Martínez Ares.

\section{LA CONSTITUCIÓN ESPAÑOLA DE} 1812. BIBLIOTECA VIRTUAL MIGUEL DE CERVANTES

www.cervantesvirtual.com/portales/ constitucion_1812

La Constitución española de 1812 es un portal temático que, bajo la dirección científica del profesor Ignacio Fernández Sarasola, de la Universidad de Oviedo, y en colaboración con Fernando Reviriego Picón, de la UNED, ofrece un amplio catálogo de textos sobre la primera Constitución promulgada en España: contexto histórico, documentos, cronología, bibliografía, estudios, imágenes y enlaces de interés.

\section{FUNDACIÓN PATRIMONIO INDUSTRIAL DE ANDALUCÍA www.fupia.es}

Organización sin fines de lucro dedicada a la salvaguardia del patrimonio industrial de Andalucía. Podrá acceder a las intervenciones realizadas por la Fundación, noticias sobre patrimonio industrial, enlaces de interés y acceso a las conclusiones de las I Jornadas Andaluzas de Patrimonio Industrial y Obra Pública, así como la II convocatoria que tendrá lugar en 2012.

INCUNA. ASOCIACIÓN DE AROUEOLOGÍA INDUSTRIAL, PATRIMONIO CULTURAL Y NATURAL

http://incuna.es/tag/patrimonioindustrial

Asociación dedicada a conocer y divulgar la arqueología industrial a través de proyectos de puesta en valor en su relación con el entorno natural, tanto en el plano local como regional o nacional. En septiembre de 2012 organizará las XIV jornadas internacionales de patrimonio industrial: Patrimonio Industrial y Paisajes Culturales. Memorias del desarrollo.

\section{PORTAL DE MUSEOS DE} ANDALUCÍA. MUSEO DE CÁDIZ

www.juntadeandalucia.es/ cultura/museos/MCA/index. jsp?redirect=S2_1.jsp

Entre las obras singulares que presenta el museo de Cádiz dentro del portal de Museos de Andalucía se encuentra e Sainete de la Tia Norica. La página ofrece acceso a actividades, exposiciones y publicaciones generadas por el museo.

\section{PROYECTO SAGENA}

www.sagena.es

Sitio web de este proyecto de investigación de excelencia cuyo objetivo es avanzar en el conocimiento histórico de la tecnología pesquera en Andalucía en el Mundo Antiguo, entendiendo como tal el periodo existente entre el origen de la Humanidad y finales de la Antigüedad Tardia, justo antes de la llegada de los primeros contingentes islámicos a la zona a inicios del s. VIII d. de C.

\section{CALLEJERAS.ES}

http://callejeras.es

Portal sobre las agrupaciones callejeras del Carnaval de Cádiz. El sitio ofrece la posibilidad de registrarse como agrupación callejera, descargar videos y escuchar el programa "Sólo callejeras" desarrollado en colaboración con la web www.carnavaldecadiz.com

EJEMPLAR DIGITALIZADO DE LA CONSTITUCIÓN DE 1812

www.puertoreal.es/Constitucion1812/ constitucion/constitucion.html

Ejemplar de la Constitución de 1812 digitalizado por el Ayuntamiento de Puerto Real (Cádiz). 